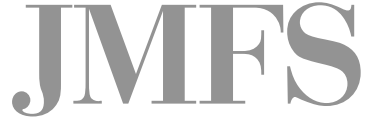

Journal of Management and Financial Sciences
Volume XI

Issue 33 (September 2018)

pp. 97-115

Warsaw School of Economics

Collegium of Management and Finance

Martin Smoliner

Institute for Railway Engineering and Transport Economy

Graz University of Technology

Stefan Walter

Department of Transport and Structures

Province of Styria

Stefan Marschnig

Institute for Railway Engineering and Transport Economy

Graz University of Technology

\title{
Optimal Coordination of Timetable and Infrastructure Development in a Liberalised Railway Market
}

\footnotetext{
ABstract

The gradual liberalisation of the European railway market has so far mainly been assessed regarding its effect on the grade of competition and market access. However, one major impact has not received much attention yet: the effects of the liberalisation on the joint development of timetables and infrastructure. This is especially crucial for countries that align their railway network according to the requirements of the Integrated Timetable (ITF). The implementation of the ITF requires a longterm planning process and network-wide cost-intensive infrastructure measures. Contrary to that, open access traffic can neither be planned in the long-term, nor is it coherent with the ITF. Recent conflicts show that the assignment of train paths for open access traffic considerably affects the system of the ITF, calling for significant timetable and/or infrastructure adaptions. For an efficient and sustainable railway system, a holistic approach is needed allowing for a combination of open access and the requirements of the ITF.

To derive a suitable methodology the status quo of the ITF-implementation and open access traffic is analysed in Austria, the Czech Republic and the Netherlands. Based on these findings, three
} 
options are identified on how open access can be integrated in an ITF-system according to the EU legislation. Advantages and disadvantages are discussed and finally the optimal procedure in terms of a sustainable network development is recommended.

Keywords: integrated timetable, long-term infrastructure development, fourth railway package, liberalisation, public service obligations, open access, self-sustaining operators

JEL-Classification Codes: R; R4; R42; R48

\section{Introduction}

The liberalisation of the European railway market has already been investigated several times. Nevertheless, effects on long-term infrastructure development are usually not covered by the existing studies. This paper presents an evaluation of a sustainable coordination of timetable and infrastructure development with a focus on passenger transport. In countries which are implementing the ITF slot allocation for passenger trains is facing tight constraints due to their strict timetable requirements. The analysis of the European railway market liberalisation [Boston Consulting Group, 2015; IBM Business Consulting Group, 2011, p. 71] usually covers market entrance conditions. According to the directive 34/2012/EWG, a single European market should be established, enabling a non-discriminatory train slot allocation across all railway undertakings. In the long run, this is to create an attractive transport system for both passenger and freight trains. This study analyses whether the goals of the EU-legislation have already been met. The aim is to present a holistic approach to investigate the joint development of both timetable and infrastructure in the long-term perspective.

\subsection{Problem statement}

Figure 1 shows the rail market structure and depicts in which countries (i) tendered or (ii) directly awarded public service obligations (PSO) or (iii) commercial open access services are offered. However, the ratio of tendered PSO or open access services to directly awarded services does not give any information about the crucial topic of timetable and long-term infrastructure development.

Nevertheless, these aspects are of special interest to policy-makers, as infrastructure development costs billions of taxpayers' money, especially in countries which align their railway network according to the requirements of the Integrated Timetable (ITF).

The ITF is perfectly suited for the needs of medium-sized countries that lack the potential for high-speed trains, but it requires a soundly designed network service. The ITF is based upon a strict schedule that consists of clearly defined hubs, which are connected by railway 
lines with systematic target riding times. A nationwide implementation of the ITF is a cost-intensive long-term investment and its implementation can take several decades.

Figure 1. Railway market structure 2012

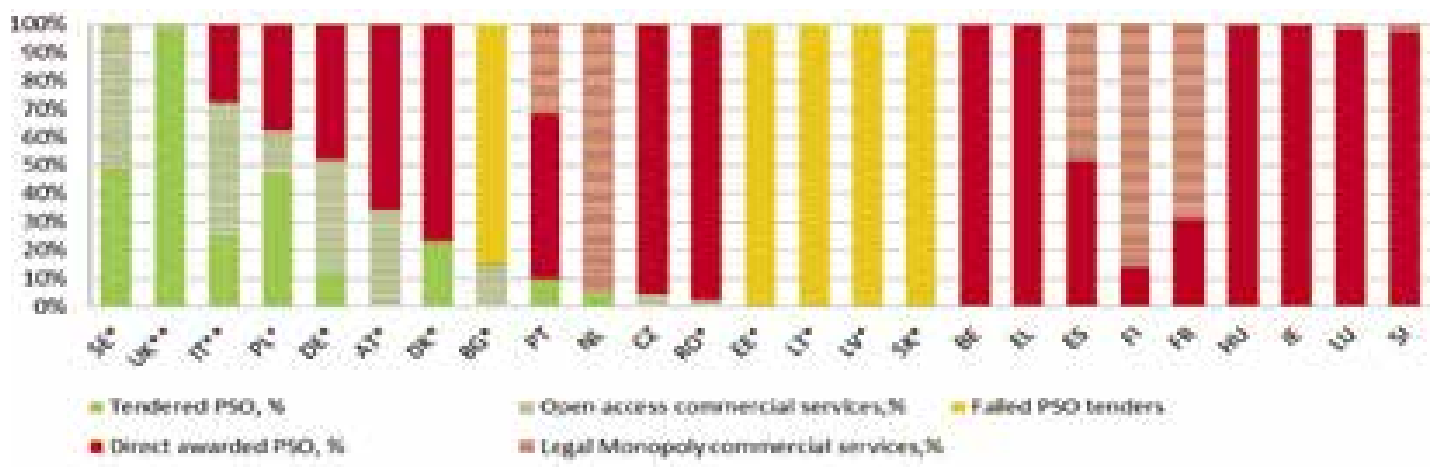

Source: European Parliament, 2016, p. 13.

For example, in Austria all infrastructure measurements are aligned with the principles of the ITF and the requirements of the target timetable 2025+. The investment volume for this undertaking amounts to $€ 40$ billion. Ongoing research is evaluating the costs of infrastructure investments in Austria directly dedicated to the ITF. Experts estimate a ratio from $5 \%$ up to $25 \%$ of the total investment costs.

Not only do infrastructure investments, such as tunnels last for about 150 years, but also tracks have service lives of more than 30 years. Yet, the length of a PSO contract does usually not exceed ten years. Moreover, train paths of railway services, especially notable for open access services, are stable for only one year. Therefore, there is a significant gap between planning horizons of infrastructure design and open access train services. As the latter cannot be planned in the long-term, there is no possibility for coherent infrastructure development and measures can only be taken in the short-term perspective. This is placing the risk of inefficiencies and stranded investments on the one hand, or investment backlogs and bottlenecks on the other hand.

\subsection{Objectives}

An optimal timetable is given if there is a coherent coordination of the ITF requirements and long-term timetable and infrastructure development. This study has a different focus than merely evaluating the status of liberalisation in the investigated countries. This approach covers the entire railway system and not only the segment of commercial train services. Approaches to handle the antagonism of the ITF and open access traffic according to the current EU legislation are to be analysed in order to derive a model that fits best the boundary conditions of the EU legislation, long-term infrastructure development and the ITF. 


\subsection{Methodology}

This paper is on the one hand based on literature research and on the other hand on expert interviews. The literature research mainly analyses legal documents like European and national law, network statements of infrastructure managers and the latest relevant scientific publications. In addition, timetables, network plans and infrastructure development plans of the respective infrastructure managers have been investigated. Furthermore, transportation scientists and traffic consultants in Austria, the Czech Republic and the Netherlands have been consulted. These expert interviews were based on the five dimensions described below.

The aim of this process is to derive experiences and procedures from the countries inspected on how to optimise the coordination of timetable and long-term infrastructure development given both the ITF and commercial open access train services. Consequently, five dimensions were developed to answer the objectives.

\section{a) How is the railway infrastructure funded?}

Railway infrastructure in a liberalised railway market can be considered state funded, since track access charges by definition only cover marginal costs [Directive 2012/34/EU]. Markups are the first exception to allow for minor additions that may only be charged in market segments with self-sustaining services. Any form of public service obligations indicates that there is no market and hence that infrastructure needs to be state-funded.

When transport services are not offered by commercial companies, but must be ordered by public authorities, there is no market. If there is no market, there cannot be any competition and infrastructure must be developed by the state. According to Directive 34/2012/EU, the Infrastructure Manager (IM) should allocate network capacity as economically efficient as possible.

In addition, it should be guaranteed that the allocation of self-sustaining services that benefit from an open market can be aligned with PSO-services.

Therefore, the first dimension is to evaluate whether the state is (i) bearing the cost for infrastructure investments and (ii) taking over the long-term service offer design.

\section{b) Which railway undertakings are competing against each other?}

While self-sustaining open access freight transport is widely spread across Europe, self-sustaining passenger transport is of minor relevance. In contrast, the share of private railway undertakings running PSO-contracts is higher by far. However, PSO-services and self-sustaining traffic pose completely different challenges to infrastructure development. RUs running under PSO-contracts usually have quite strict specifications regarding their timetables. Railway lines with both self-sustaining services and PSO-services challenge both infrastructure development and management. The situation is easier on lines without self-sustaining traffic, where the development and management of infrastructure only need to be coordinated with the public authority. 
This dimension is to define the competitors and whether this competition has an impact on infrastructure development.

\section{c) What does the conflict resolution process look like?}

The allocation of infrastructure capacity inevitably leads to conflicts of identical or overlapping train path requests. Infrastructure managers are obligated by Directive 2012/34/EU to allocate capacity in a transparent and non-discriminatory way, while guaranteeing an efficient use of the infrastructure. Most countries seek a consensual solution of conflicts. However, if conflicts cannot be solved in this process, different procedures have been developed. This dimension should clarify the criteria used and in which order slots are allocated. This raises several issues of (i)

- treatment of self-sustaining and PSO services; (ii)

- treatment of international trains; (iii)

- hierarchy of passenger and freight trains; and (iv)

- application of priority criteria or economic algorithms in case of conflicts.

\section{d) What triggers infrastructure measures?}

Market accessibility is a matter that needs to be dealt with at the level of train path management and railway undertakings. However, neither the one nor the other is responsible for demand modelling, the need for network extension or general transport planning [Marschnig, 2016]. Therefore, the question of market accessibility cannot cover macroeconomic issues. Nevertheless, the question of what triggers infrastructure investments remains unsolved. We can distinguish two main scenarios. If train paths are planned at the long-term level, longterm infrastructure development is possible. If path allocation is the result of individual path requests, the result will be a congested infrastructure, which can be solved only by reactive infrastructure measurements.

The first scenario implies long-term infrastructure development by public authorities. The second scenario allows the only path allocator and infrastructure manager to plan measures for capacity enhancements. Once measures have been derived, they need to be forwarded to the respective authority. This process requires a close cooperation of these separate bodies.

This dimension is to illustrate how and in which form development of railway lines is triggered and how the coordination of timetable and infrastructure development is accomplished.

\section{e) How to handle stranded investments?}

The planning, adaption, and building of railway infrastructure is a long-term process on all stages. Therefore, resources for planning and building are bound for several decades. It has to be considered that the scope of commercial railway undertakings is limited little more than a year, sometimes even less. Due to this discrepancy, building infrastructure needs to be done ahead for predicted traffic, which could imply stranded investments. Contradictory to that, there is a risk that infrastructure development cannot react upon the needs of the market 
in time. Both scenarios imply cost-intensive impacts on public funds. The sole question of market accessibility does not cover this issue at all.

The purpose of this dimension is to describe how this difficulty is covered in the context of a liberalised railway market.

\subsection{Approach}

To derive a suitable methodology for the status quo of the ITF-implementation and open access traffic, the five dimensions named are applied to Austria, the Czech Republic and the Netherlands. Based on the findings, options are identified on how Open Access can be integrated in an ITF system in accordance with the EU legislation. Advantages and disadvantages are discussed and finally the optimal procedure in terms of sustainable network development is recommended.

\section{Case studies}

The questions described before are applied to Austria, the Czech Republic and the Netherlands. The railway system in each of these countries is based on the ITF, while the grades of liberalisation vary.

\subsection{Austria}

\section{Ad a)}

The Austrian railway infrastructure (renewal, extension, maintenance and reinvestment) is fully financed by the railway infrastructure manager (IM) which is on most lines ÖBB-Infrastruktur AG, and some minor local IMs. Renewal and extension of the network are funded by state guaranteed loans or direct state investments. Track operation is partly covered by track access charges and complemented by state subsidies [Act, 2009/95/ BGBl, art. 63]. While the IM is required to run the infrastructure on a cost-efficient basis, network alterations are driven by political considerations.

\section{Ad b)}

Access for self-sustaining train operators in passenger services is well established in Austria. According to the liberalisation index, Austria was ranked "advanced" even before the "Westbahn" RU entered the market [IBM, 2011, p. 50, p. 71]. The mentioned RU started a commercial train operation on the Wien-Salzburg line in 2011. The former incumbent ÖBB PV AG is running self-sustaining long-distance trains that serve as a backbone for the national Integrated Timetable (ITF). Furthermore, in 2017 "RegioJet" started operating on 
the Praha-Wien line (figure 2). There is no public tendering for Public Service Obligations (PSO) yet, all contracts are directly awarded. The planning of the service offer is done by the seven regional authorities in cooperation with the federal ministry and its planning affiliate.

\section{Ad c)}

Track allocation is carried out by the ÖBB-Infrastruktur AG - Department Netzzugang and the railway regulator as the highest authority. The latter had to clarify several cases in the past, two of which are described below. The non-discriminatory allocation is done in several stages. According to Austrian law, symmetrical integrated train paths are preferred in general, no matter whether a line is congested or not. In case of congestion, passenger transport is preferred during peak hours. Finally, trains are ranked according to the importance of the service for the society. Henceforth, long-term framework agreements are considered.

\section{Figure 2. Self-sustaining services and PSO-services in Austria}

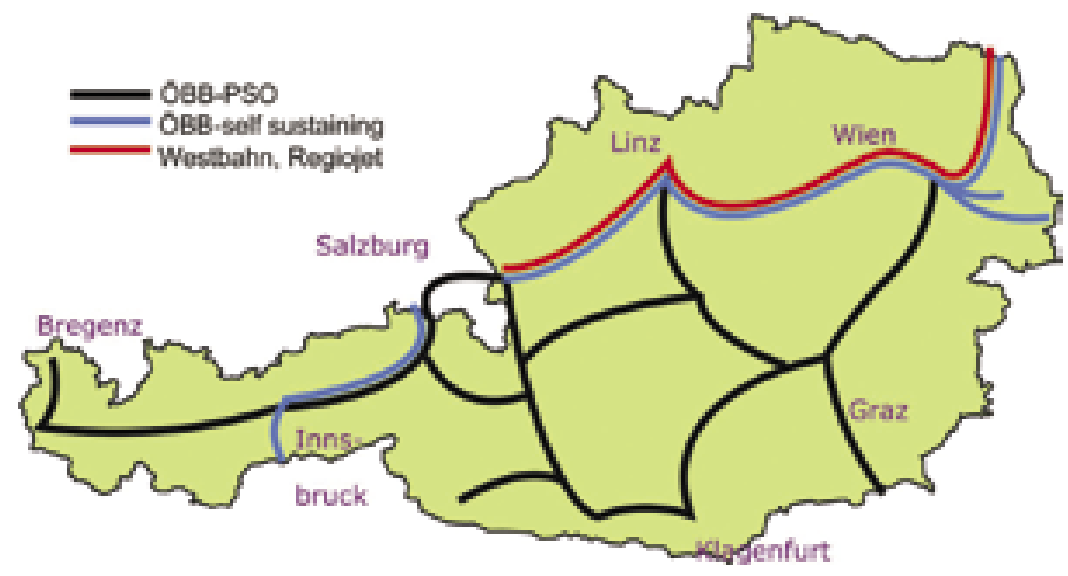

Source: the authors' own material.

Given the infrastructure is not congested, symmetrical train paths are preferred, followed by framework agreements and thereby international and integrated trains at the same level. Integrated timetable passenger trains are preferred if they connect three consecutive hubs [ÖBB-Infrastruktur AG, 2017]. This logic is setting, yet low, a barrier to commercial train operators entering the market. Long term planning for the tendering authority and railway undertakings (RUs) is still almost impossible, as framework agreements are of minor importance in the track allocation process.

This situation is shown by two cases:

1. The rule of prioritising connections that serve three consecutive hubs has to be executed non-discriminatorily. Both the incumbent and Westbahn run a half-hourly interval each between Vienna and Salzburg at almost the same timeslots, only separated by a few minutes. As the hub spread time is not defined by a precise time but a loosely defined frame, both operators are able to meet the requirement to serve three consecutive hubs 
while running at almost the same time. However, either RU can only serve half of the hub (either toward or from the hub) each, but only the incumbent offers through tariffs. The lost network connections on regional branch lines have to be replaced by additional service orders and even some bus replacements.

2. While originally regional passenger trains were preferred on the S-Bahn trunk line in Vienna, the latest network statement prioritises all passenger services irrespective of their purpose. This allows Westbahn to run its half-hourly long-distance trains on the trunk, significantly reducing capacity for regional S-Bahn services and contradicting the regional transport planning [IBM Business Consulting Services, 2011].

These cases show that predefined prioritisation of integrated services by law, since it cannot cover all cases a priori, does neither ensure the implementation of a nation-wide ITF nor the planned usage of infrastructure.

\section{Ad d)}

The long-term planning horizon of the target network set by the government is defined by the year $2025+$. In addition, there are stages of infrastructure development predefined up to 2040 [ÖBB-Infrastruktur AG, 2011, p. 83]. These plans are based on a nationwide ITF that covers all infrastructure measures for passenger transport. This is the fundament for infrastructure framework agreements between ÖBB-Infrastruktur AG and the government, planning six years ahead. The government takes care of developing and updating plans for the target network.

\section{Ad e)}

The risk of infrastructure investments is covered by the state, which also plans strategic train paths. At the moment, there is no concept of how to deal with self-sustaining train paths that do not fit into a nationwide ITF. This potentially (and, given the experience, presumably) implies that there is not enough capacity for self-sustaining services outside the ITF schedule without interfering with its long-term perspective.

\subsection{The Czech Republic}

\section{Ad a)}

The Czech railway infrastructure is managed by SŽDC, which owns, operates and develops the railway infrastructure with state subsidises [SŽDC, 2016] Extension, investments and maintenance are defined in the policy paper of the Czech government [Ministerstvo dopravy, 2013] including a long-term perspective up to the year 2050. Railway undertakings pay comparably low track access charges. Until 2016, most stations had been owned by the former incumbent České Dráhy (ČD), but were bought by SŽDC in 2016 with state subsidies. Almost all recent infrastructure projects are co-financed by the EU [SŽDC, 2018]. 


\section{Ad b)}

Due to low track access charges, no station service fee and high priority for long-distance trains in the slot allocation process, the main route of the Czech railway network between Praha and Ostrava became the busiest line in terms of open access service in Europe [Tomeš, Kvizda, Nigrin, Seidenglanz, 2014, p. 273]. In 2018, four commercial RU operate trains on this line: the former incumbent ČD, Leo Express, RegioJet and Arriva (Figure 3). While the latter only runs one train per day, the other RU offer hourly services during peak hours. The services have different destinations, including Ostrava, Kraków, Žilina, Košice, Bratislava and Wien. Arriva operates up to two long-distance trains per day from Praha to Nitra, as well as express trains from Praha to Benešov $u$ Prahy. The market share of private operators on the Praha-Ostrava line is estimated to be more than 50\% [Nash, Tomeš, Jandová, 2015, p. 352].

Long distance services on other routes as well as regional train services are competitively tendered but more often directly awarded [Tomeš et al., 2014, p. 272].

\section{Figure 3. Self-sustaining services in the Czech Republic}

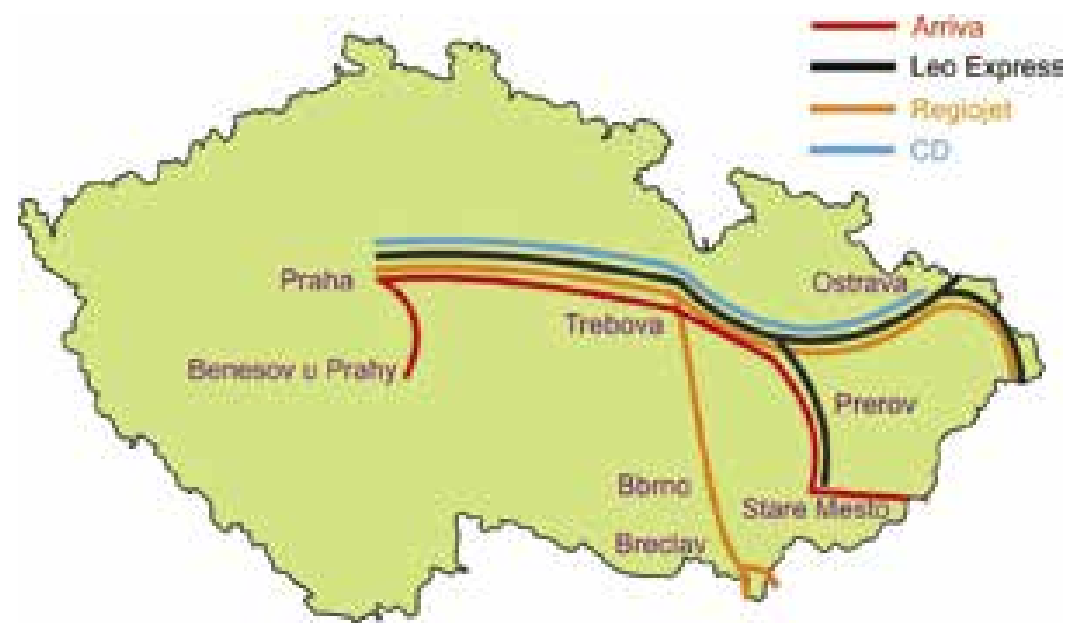

Source: the authors' own material.

\section{Ad c)}

SŽDC is the responsible body for the allocation of railway infrastructure capacity. In case of a conflict, a four-stage process is applied. If requests of applicants cannot be satisfied within the coordination process, the IM allocates capacity first to services ensuring transport needs of the state or region. Then, combined transports and framework agreements are considered, followed by international passenger and freight transport. If no solution is found, a priority catalogue is applied: international trains and herein long-distance trains are preferred over regional trains. Further, periodically running trains are preferred, followed by transport services applying for the higher number of train path kilometres, and finally, a better connectivity 
of timetables is considered. If there is still no agreement, a conflict resolution process led by the rail authority is started and the relevant infrastructure has to be declared as exhausted.

The logic of the allocation causes issues regarding infrastructure development but also affects the quality of the network-wide train operation.

The main route between Praha and Česká Třebová is declared as "overloaded", but not congested. A high-speed line between Praha and Brno is thought to be the long-term solution but there is no efficient short-term capacity upgrade. Furthermore, an upgraded main line would question the economic efficiency of the high-speed line. In addition, line upgrade works would drastically reduce the number of train paths for years. Therefore, RUs are interested in arranging themselves within the framework of the conflict resolution process, while the IM is able to declare the timetable to be constructible [Janoš, 2018].

Basically, PSO-services take precedence over open access products [Janos, Baudys, 2013, p. 89]. As the slot allocation is also linked to train categories, PSO-services in certain cases are treated like self-sustaining trains. According to the regulation, commercial long-distance trains are then prioritised over regional trains. This causes frequent overtaking of regional trains leading to extended travel times and less possible transfer connections of ordered services [Tomeš et al., 2014, p. 273]. Even though prioritised, commercial trains are less relevant to be integrated in the ITF as they usually have no continuous pattern over the years as intervals and departure times change frequently [Janoš, Baudyš, 2013, p. 89].

\section{Ad d)}

In the post-communist era since 1995, the Czech railway network has seen heavy infrastructure investments, focussing on the main corridors and aiming for reduced travel times between the main cities. The network timetable is based on the ITF; however, there have hardly been any investments to increase capacity of the railway network around the main cities, which is nowadays posing a challenge to integrate both commercial and PSO traffic [Tomeš et al., 2014, p. 273]. Minor investments on the secondary network are based on the concepts established between 2004-2009 and fit the requirements of the ITF but have never been institutionalised. The measures for the next years and a long-term perspective can mainly be found in the government's strategy paper [Ministerstvo dopravy, 2013]. While most of the investments fulfil the criteria of the ITF, the focus still lies on upgrading the main corridors [Janoš, 2018, Interview].

\section{Ad e)}

Failed infrastructure investments caused by open access operation have not been the case yet. Especially frequent short trains during peak hours cause a lack of capacity on the main line and lead to an unstable timetable. Additionally, heterogeneity, caused by commercial operators, lowers the capacity [Janoš, Baudyš, 2013, p. 90]. To prevent additional capacity constraints a proof of financial equilibrium needs to be provided in case an additional RU 
would apply for slots on the main line. Furthermore, introduction of the concession principle is currently being discussed [Janoš, 2018].

\subsection{The Netherlands}

\section{Ad a)}

Maintenance, renewal and extension of the railway network are done by the state-owned IM ProRail. Station incomes and track access charges cover about one third of ProRail's expenses, while the rest is funded by government subsidies [Marschnig, 2018]. Track access charges for regional services are covered by the state through regional authorities which are responsible for regional railway services. The intercity network is operated by Nederlandse Spoorwegen (NS) as a self-sustaining train service. Therefore, track access charges are covered by NS itself [Kummer et al., 2013, p. 95].

\section{Ad b)}

NS is directly awarded a concession with exclusive rights by the ministry for the self-sustaining Intercity lines, representing the core of the Dutch railway network. Regional lines are tendered by local entities granting exclusive rights [Kummer et.al, 2013, p. 94]. The only commercial train service at the national level was operated by Lovers Rail between Amsterdam and Haarlem between 1996 and 1999 [Finger, 2012, p. 80]. The service was discontinued after three years, as it had not been attractive for customers nor was it financially sustainable. Since this had represented a worst-case scenario of open access, it strengthened both the position of NS and the government's reluctance towards open access operation [van de Velde, 2018, Interview].

Direct awarding with exclusive rights is supposed to guarantee efficiency and allow for optimisation of operations in the network. Public tendering of the Intercity network would imply a separation of the network in different lines which is seen as being inefficient and jeopardising the economic equilibrium [van de Velde, 2018, Interview].

The situation is different for international connections, where several commercial services are offered. Thalys runs an hourly service on the High Speed Line Zuid from Amsterdam to Paris. Eurostar offers two connections per day on the same line between Amsterdam and Bruxelles. Regular two-hourly Intercity services are offered between Amsterdam and Berlin as well as two hourly ICE connections between Amsterdam and Köln. From 2009 to 2013, a subsidiary of NS International, KLM and SNCB/NMBS, called Fyra, offered services between Amsterdam and Bruxelles. Due to technical problems, the service was discontinued. Therefore, the Intercity Direct between Amsterdam and Breda, operated jointly by NS and SNCB/ NMBS, became the only remaining service (Figure 4). 
Figure 4: Self-sustaining services in the Netherlands

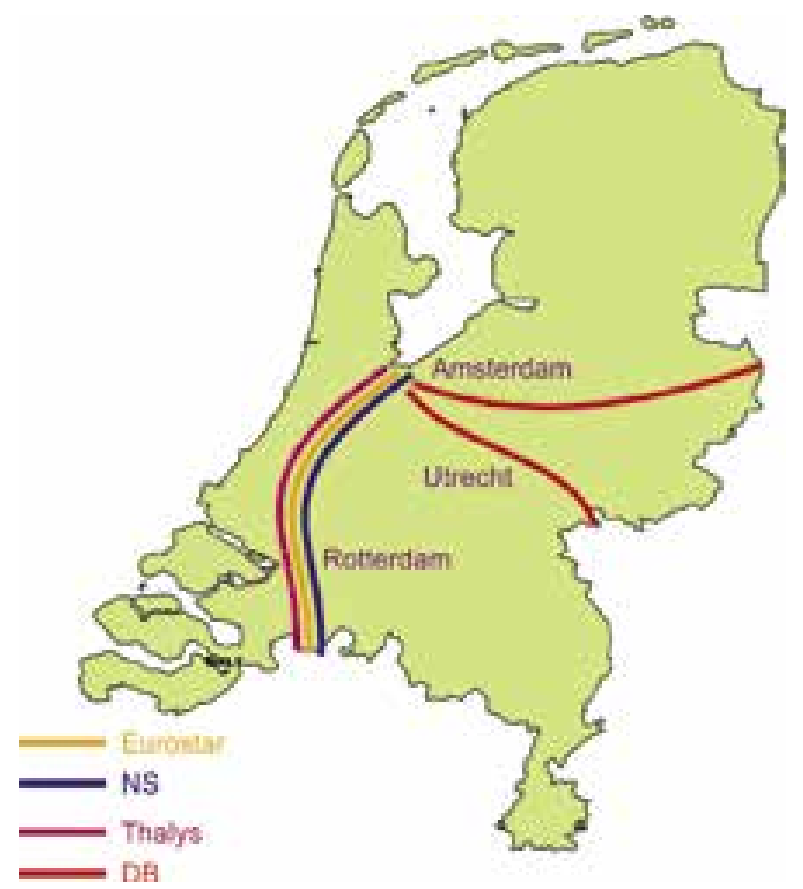

Source: the authors' own material.

Ad c)

The allocation of train slots is done by ProRail in a two-stage pattern [ProRail, 2017]. First, a basic hour pattern (BHP) is defined. RUs voluntarily join this process to coordinate requests amongst each other. ProRail facilitates this process if RUs cannot solve conflicts amongst each other. Freight train paths created in this phase are published on the website of the respective corridor organisation for which the prearranged paths are intended.

The actual annual timetable allocation process is based on the prearranged paths for freight corridors and the results of the BHP. RUs that took part in the BHP receive preferred treatment. Furthermore, as many attractive cross border connections as possible should be offered. In case of conflicts, ProRail adapts requests according to predefined operational rules. If no satisfying solution is found a coordination process involving the applicants is started. In case this does not result in a solution the respective section will be declared as congested infrastructure. Consequently, priority rules are applied. Herein transport takes precedence over traffic. Distinctive freight trains are considered, finally daily services are preferred over irregular services.

While there are several periodisation rules for freight trains, the allocation of passenger trains is quite vague. As NS has exclusive rights on the core-network it is relatively autonomous in setting the timetable. Regional tendered services need to adapt their timetables in order to guarantee attractive connections to the Intercity trains [Kummer et al., 2013, p. 94]. 
Commercial international services run on a different network (Thalys, Eurostar and Intercity Direct) or are well integrated in the Intercity-scheme (IC and ICE).

Ad d)

A long-term rail agenda was decided upon in 2014, defining medium-term goals until 2028 and long-term planning until 2040. It addresses the goals of (i) capacity upgrade, (ii) increasing of maximum speed and (iii) station upgrades, but it lacks an overall joint timetable and infrastructure development perspective [Minsterie van Infrastructuur en Milieu, 2013, p. 26]. In general, there is no notable interaction between infrastructure investments and the ITF beside regional upgrades like the Groningen line, where the ITF posed a major factor in the planning process. In this specific case, infrastructure was adapted to the needs of the ITF and additional trains were ordered. However, there are plans to further expand the frequency on the IC-connection to six trains per hour in the core Intercity network. Therefore, ProRail is evaluating the timetable in order to derive infrastructure needs [van de Velde, 2018].

\section{Ad e)}

The risk of stranded investments is covered by the state. For example, the High Speed Link Zuid was built as a PPP, with the state covering maintenance, operation and renewal for 25 years. The line, constructed for a maximum speed of $300 \mathrm{~km} / \mathrm{h}$, was criticised for not fitting into the Dutch railway network. While intended to be an attractive international line, it is still predominantly used by domestic passengers. Since a clear operational concept is missing, an upgrade of the existing line between Amsterdam and the border to Belgium to four tracks is widely seen to have been a more sustainable option [Van de Velde, 2018].

\subsection{Findings of the case studies}

While the Austrian transport policy is fundamentally reliant upon the ITF, self-sustaining train services have a crucial impact on the network effectiveness of the ITF. As self-sustaining services require the adaption of the system train paths, connections cannot be served anymore. Furthermore, self-sustaining long-distance services cause severe capacity constraints on regional lines.

The situation is similar in the Czech Republic. While competition in the railway sector led to higher frequency on the main route, service was concentrated in the peak hours, night trains were reduced and stops in medium-sized cities were cancelled [Tomeš et al., 2014, p. 273]. While travelling on the main lines and between the major cities became more attractive, there are negative effects on a network-wide scope [Baudyš, Janoš, 2013, p. 90]. Self-sustaining train services caused a gradual transformation from a regular interval timetable to a demand driven timetable with significant differences of the frequency between peak hours and non-peak hours [Nash et al., 2015, p. 352]. Additionally, commercial services question the financial stability of PSO-services and complicate timetable construction [Tomeš et al., 2014, p. 275]. 
In contrast to the issues raised in Austria and the Czech Republic, the situation is quite different in the Netherlands. Train services of the core network are run in a concession system with exclusive rights. Therefore, no private RU operates domestic services. International operators run on a separated high-speed line or fit in the scheme of the ITF. Therefore, there are hardly any conflicts in capacity allocation and the timetable is predictable.

The coordination of self-sustaining trains with the requirement of the ITF works neither in Austria nor in the Czech Republic as strategic planning on how to implement the ITF in a liberalised railway system does not exist. This problem is avoided in the Netherlands, where domestic self-sustaining services are simply not allowed.

It can be deducted that short-term oriented commercial train services do not fit the ITF based on long-term infrastructure investments. The long-term planning and investment process of railway infrastructure is difficult if not impossible, to combine with open access services [van de Velde, Augustin, 2014, p. 242].

Compared to aviation, the railway sector is predominantly characterised by network relations rather than by point-to-point connections. Therefore, it is crucial to devise well-thought out strategies for "the rules of the game" and favour the realisation of network benefits [van de Velde, 2014, p. 39]. Even the limited British experience of open access traffic shows that commercial trains cause insufficient track capacity, a lack of integrated timetables and loss of economics of density [Nash, Tomeš, Jandová, 2015, p. 354]. Concluding, the presented case studies as well as further research show that the rail sector is not suitable for a completely deregulated environment [Smoliner, Walter, Marschnig, 2018].

\section{Approaches for the ITF in context of a liberalised railway system}

The declared goal of the European Commission is to increase the modal split for railways and to increase the share of private operators in the railway sector. To allow for a market accessibility coherent with the requirements of the ITF and long-term infrastructure development, three different approaches are derived.

\subsection{Concessions}

The example of the Netherlands shows that an ITF system can be successfully implemented by a concession system with exclusive rights. Furthermore, the British franchising system is arranged similarly, leaving niche segments open for self-sustaining open access trains [Davies, 2017, Interview]. In the Czech Republic, it is discussed to implement a concession system with exclusive rights for long-distance passenger transport [Janoš, 2018]. However, these considerations are aligned with the Fourth Railway Package only with narrow borders as 
exclusive rights are solely permitted if the economic equilibrium of a public service contract were compromised by an additional service [Directive 2016/2370/EU].

\subsection{System train paths}

System train paths force RUs to choose out of a catalogue of train paths instead of applying for individually designed train paths. System train paths need to be precisely defined regarding travel times and hub service times to guarantee the full functionality of the ITF. Furthermore, these system train paths should be given away only in periodic series of train path bundles, so as to consider efficient operating schedules and prevent cherry-picking of rush-hour paths only. However, restrictions apply to how precisely a system train path can be described, so to prevent a predetermination on exact vehicle properties, and thus operators.

The demand for these system train paths needs to be soundly predicted to minimise the risk of providing unused capacity. However, due to volatile self-sustaining traffic, there is still a risk of short-term market interruptions, causing unused train paths or lost transfer connections. In addition, to guarantee a continuous ITF-timetable, additional services in off peak hours need to be ordered by PSO-contracts, if their service is not made compulsory within the path assignment.

This raises the question which distribution procedures are feasible and how system train paths are guaranteed without raising conflicts in the capacity allocation process.

System train paths could be offered by the IM in a train path catalogue with staggered cost levels according to the predicted demand. If two or more RUs apply for the same train path in peak hours, a priority catalogue is to be established, ranking path requests according to the amount of off-peak services offered, capacity usage, overall benefit, etc.

To prevent conflicts in the train allocation process, the IM could declare the respective lines as congested infrastructure. Article 47 of Directive 2012/34/EU states that "priority criteria shall take account of the importance of a service to society relative to any other service which will consequently be excluded." System train paths within this definition framework represent important services as they are the backbone of an integrated network-wide service offer. However, if the respective section has been declared congested, a capacity analysis including upgrade plans is requested. This, in turn, could be used to clearly specify the future timetable development as the means of capacity enhancement.

A similar approach is to charge predefined system train paths with higher track access charges. If self-sustaining passenger trains operate on a certain line it can be assumed that revenues are high enough to raise mark-ups. According to Directive 34/2012/EU this could be then utilised to distinguish between system train paths and complementary train paths. Railway undertakings interested in providing integrated services with network-wide connections would need to pay more. RUs preferring direct point-to-point services would go for the cheaper non-system train paths. However, this system (i) would require an integrated ticket 
system for all RUs in order to guarantee an attractive network for customers, and (ii) requires some kind of a refund system for PSO contracted railway services.

The third approach is to sell system train paths per auction, as it is known of other infrastructure networks. As mentioned above, a set of train paths, rather than singular ones, needs to be offered in order to prevent cherry-picking or harming competitors by acquiring useless train paths. There is evidence that this would only work if there is a large number of homogenous train path requests. Furthermore, market accessibility is seen to be guaranteed best by easy and predictable structures, which is not the case with an auction-based system [Tanner, Mitusch, 2011, p. 19].

\subsection{PSO}

The aforementioned approaches pose several issues regarding legal feasibility, unattractive off-peak train paths, volatile behaviour of self-sustaining operators, predictability of auctions or low demand. Furthermore, self-sustaining train services are not actually self-sustaining. Full costs of infrastructure wear are not charged but covered by state subsidies [Marschnig, 2018]. Trains under PSO contracts can be defined exactly according to the requirements of the ITF and goals of the transport policy. Furthermore, they help to reduce the risk of stranded investments or underutilisation of cost intensive infrastructure. Nevertheless, PSO-services need to be preferred in the process of path allocation as described above. If the network is not tendered as a whole, periodic train path bundles should be offered.

The amended Article 11 of Directive 2012/34/EU allows for a limitation of the right of access if the economic equilibrium of a PSO-contract were compromised. However, it can be assumed that lines attracting self-sustaining operators are financially sustainable for more than one operator. An extensive economic investigation would be necessary to verify this theory. This can be applied if several RUs compete with a PSO-service like it is the case in Austria and the Czech Republic.

\subsection{Conclusion}

In the consideration of the $4^{\text {th }}$ railway package, the requirements of the ITF, and advantages and disadvantages of the analysed approaches, PSO contracts fulfil the criteria of joint longterm development of timetable and infrastructure best. PSO contracts guarantee a coherent network-wide application of the ITF as well as the highest network-wide benefits. The prerequisite is that PSO-services are preferred against self-sustaining services in any case. This allows for an efficient use of taxpayers' money and for long-term timetable and infrastructure development.

Furthermore, the size and classification of train path bundles need to be evaluated on the basis of attractive direct connections, circulation of rolling stock and other parameters. Manageable sizes will attract private companies in the tendering process. To elaborate on this, further research is required. 
However, PSO contracts are granted for a long period of time, compared to train path stability, and therefore reduce the free market. If there is a centrally planned ITF that only allows rather unattractive train paths for open access service, self-sustaining services need to accept remaining capacity, possibly jeopardising the idea of increasing the overall service offer quality. As private initiatives should benefit from a liberalised railway market, attractive train paths should be provided for self-sustaining services as well. This could result in only minor market segments to be served with open access, unlikely to be sustainably successful. Alternatively, attractive train paths need to be figured out in extensive conciliation processes.

This calls for a hybrid regime, which combines competitive tendering and open access traffic [van de Velde, Augustin, 2014]. In addition to public tendered PSO self-sustaining services could cover niche products, supplementary or high-quality services or operate in separate market segments [Janoš, Baudyš, 2013, p. 89].

Nevertheless, this means that the intention of the European Commission that self-sustaining train services will improve the railway system was wrong.

\section{Summary}

The ITF requests long-term and cost-intensive infrastructure development based upon strategic long-term timetable development. The case studies in Austria and the Czech Republic provide evidence that self-sustaining services without regulation are not compatible with the ITF and pose severe challenges to ITF timetables and the predictability of long-term infrastructure development. Consequently, strategies according to the current EU legislation have been analysed in order to derive a sustainable and sufficient solution. Finally, publicly tendered PSO contracts for system train paths are recommended to provide the optimal timetable. To optimise network-wide benefits and provide efficient services, operational parameters of PSO-bundles need to be covered in further research.

This approach allows for long-term strategic infrastructure development and efficient ITF-timetabling. Furthermore, public tendered PSO-contracts will be open for all RUs and self-sustaining traffic is guaranteed, however regulated.

\section{References}

\section{Legal documents}

1. European Union: Directive 2016/2370/EU amending Directive 2012/34/EU as regards the opening of the market for domestic passenger transport services by rail and the governance of the railway infrastructure, Directive 2016/2370/EU, 23.12.2016.

2. European Union: Directive 2012/34/EU establishing a single European railway area (recast), Directive 2012/34/EU, 21.11.2012. 
3. Republic of Austria: BGBl 95/2009: Bundesgesetz zur Neuordnung der Rechtsverhältnisse der Österreichischen Bundesbahnen (Bundesbahngesetz), BGBl 95/2009, 19. August 2009, $\$ 42$.

\section{Compact publications}

1. Baudyš, K., Janoš V., Pospíšil. J., 2009. Railway Timetable in Czech Republic. In: Proceedings of the 6th International Scientific Conference Transbaltica 2009, pp. 7-10.

2. Boston Consulting Group, 2015. The 2015 European Railway Performance Index Exploring the Link Between Performance and Public Cost.

3. Finger, M., Rosa, A., 2012. Governance of competition in the Swiss and European Railway sector. St. Gallen, p. 80.

4. IBM Business Consulting Services, 2011. Rail Liberalisation Index 2011 - Market opening: comparison of the rail markets of the Member States of the European Union, Switzerland and Norway. Brussels, p. 50, p. 71.

5. Janoš V, Baudyš K., 2013. Issues of Periodic-Timetable Construction on the fully liberalized railway market. In: Scientific Proceedings XXI. International Scientific-Technical Conference "trans \& MOTAUTO 13, p. 89.

6. Minsterie van Infrastructuur en Milieu, 2013. Lange Termijn Spooragenda. Visie, ambities en doelen, p. 26.

7. Kummer, S. et al, 2013. Ausschreibungswettbewerb im europäischen SPNV - Was kann Österreich aus den Erfahrungen von Ausschreibungen in Europa lernen? Wien: Endbericht.

8. Marschnig, S., 2016) iTAC - innovative Track Access Charges. TU Graz.

9. Ministerstvo dopravy, 2013. Dopravni politika ČR pro obdobi 2014-2020s vhledem do roku 2050. Duben.

10. Nash C., Tomeš Z., Jandová M., 2015. Experiences with Railway Regulation in Great Britain and the Czech Republic - Round Table Report. Review of Economic Perspectives, Vol. 15/4, p. 352.

11. ÖBB-Infrastruktur AG, 2017. Schienennetznutzungsbedingungen 2018 der ÖBB-Infrastruktur AG (Network Statement 2018). Vienna, p. 42.

12. ÖBB-Infrastruktur AG, 2011. Zielnetz 2025+. Vienna, p. 83.

13. ProRail, 2017. Network Statement 2018.

14. Smoliner M., Walter S., Marschnig S., 2018. The Optimal Coordination of Timetabling and Infrastructure Design, Part I. ZEVrail, 142/4.

15. SŽDC, 2016. Annual Report 2016. Prague, p. 31.

16. Tanner A., Mitusch K., 2011. Trassenvermarktung. Auktion versus Listenpreisverfahren. Internationales Verkehrswesen 63/3, p. 19.

17. Tomeš Z., Kvizda M., Nigrin T., Seidenglanz D., 2014. Competition in the railway passenger market in the Czech Republic. Research in Transportation Economics 48.

18. van de Velde D., Augustin K., 2014. Workshop 4 Report: Governance, ownership and competition in deregulated public transport markets. Research in Transportation Economics 48, 2014.

19. van de Velde D., 2014. Market initiative regimes in public transport in Europe: Recent developments. Research in Transportation Economics 48. 
20. SŽDC, 2018, Projects overview, [online] http://www.szdc.cz/en/modernizace-drahy/spolufinancovani-z-eu.html [accessed: 24.04.2018].

21. Marschnig S., 2018. Direct cost - a first Benchmark, [online] https://events.railtech.com/wpcontent/uploads/2018/04/TAC2018_Marschnig_FirstBenchmarkonDirectCost_04042018_ Handout.pdf [accessed: 25.04.2018]. 
